\title{
Environmental Management Systems in Construction Projects in Kenya: Barriers, Drivers, Adoption Levels
}

\author{
Onkangi N. Ruth ${ }^{1}$, Nyakondo N. Stephen ${ }^{2}$, Mwangi Peter ${ }^{3}$, Ondari Lilian ${ }^{4}$, Wangui Ng'ang'a ${ }^{5}$, Wachira Bore \\ ${ }^{1}$ Research Officer-National Construction Authority; konkangi@gmail.com, ${ }^{2}$ Senior Research Officer-National Construction \\ Authority: s.nyakondo@nca.go.ke, ${ }^{3}$ Senior Research Scientist Kenya Wildlife Service: PNjiiri@kws.go.ke, ${ }^{4}$ Structural \\ Engineer, University of Toledo: nyanchyond@gmail.com, ${ }^{5}$ Co-founder and director, EcoRafiki: samwan31@gmail.com' \\ ${ }^{6}$ Environmental Inspector-National Environment Management Authority: Wachirabore@nema.go.ke
}

Abstract: The construction industry is established to be responsible for one third of Green House Gas (GHG) emissions and has an oversized carbon footprint which is attributed to the industry's large materials' appetite. The industry is heavily reliant on natural resource utilisation and is reported to contribute over 33\% of waste materials in the landfills. Kenya seems to be fighting a losing battle with poor management of natural resources, waste management, inter alia environmental impacts associated with; the extraction, transport, processing, fabrication, installation and disposal of the building industry materials.

Waste management and handling of hazardous material is a menace to rapidly developing nations. To keep economic progress in its path, sustainable resource use and responsible waste management is needful. Action needs to be stirred in the construction sector as the major polluter. Sound and practical management of environmental matters cannot be decoupled from enterprise risk management. Therefore, corporate governance in construction firms needs to adopt responsible resource consumption and production for overall sustainable growth and development.

In an effort to understand and address this problem at source, this study evaluated the level of fusion of business and environmental goals in the construction sector in Kenya. It critically examines at project level, Environmental Management Systems (EMS) employed by established and new entrant construction firms, with a focus on waste management, hazardous material (HazMat) waste handling, barriers and drivers of environmental performance as well as level of inclusion of environmental aspects in product design in the construction firms in Kenya.

The paper further, proposes solid ways to broaden and enhance the quality of environmentally conscious infrastructure in developing nations like Kenya.

Keywords: construction, demolition, waste, policy, sustainability, barriers and drivers

\section{Introduction}

Integrating environmental concerns in construction is not very popular in the developing world as most construction firms and property developers are driven by short term cost-benefit considerations [1]. Most perceive environmental concerns to be a soft issue while addressing them is also seen to add to project costs. The construction sector throughout all its processes has an oversized ecological footprint and is intensely resource dependent. Materials used in the industry are sourced from nature, ironically the industry contributes $50 \%$ of the landfill waste that damages nature and compromises its integrity and ability to support its dependents [2] the sector appears to be biting the hand that feeds it. Therefore, the industry is likely to be adversely impacted by unsustainable resource utilisation even as it exacerbates environmental degradation. 
Integrating environmental concerns in infrastructure development addresses the problems associated with construction at source. It seeks to minimize non-renewable resource consumption, enhance the natural environment and eliminate the use of toxins. It is an incredible solution that immensely pays for itself! The future of problems associated with degradation and irresponsible natural resource use grows grim when considering more infrastructure network is yet to be built or expanded in developing nations. With the little existing coverage, the ecological footprint is oversized, on continuation with the remaining, the aftermath looks unattractive if developing countries continue developing unsustainably.

For a sector whose activities are resource dependent and linked with a broad spectrum of negative environmental impacts, enormous external environmental costs [3] and negative externalities: EMS is imperative as a tool to mitigate environmental impacts as well as to inculcate sustainability [4]

With increased environmental degradation, environmental concerns are gaining prominence in the construction sector, globally. Accordingly, it is becoming increasingly vital for construction firms to proactively manage environmental aspects of projects in construction, operation and demolition phases as this is part of enterprise risk management [1, 5]. Global trends indicate that unlike manufacturing entities, few construction firms have fully implemented EMS system. This is attributed to long term stability enjoyed by the manufacturing industries and a perennial focus of environmental regulation on this sector [7]. The focus has previously been on manufacturing and agricultural industries, but with growing realisation of the adverse and long-term negative impacts posed by the construction sector, environmental management policies, laws, multilateral environmental agreements (MEAs) are looping in the construction sector.

Adopting environmental management systems is minimal and speckled in the construction sector. Even in the presence of policy, attitudes and perceptions to environmental management influence compliance and implementation by industry players. Pockets of leadership are witnessed in various projects mostly due to strict policies by international funders. Stipulations in country policies are entry level as far as environmental management systems is concerned, nonetheless, aspirations to environmentally sound, resource efficient projects are extremely low. Environmental management systems are set out broadly in local regulations but full-scale implementation is lacking.

Environmental stewardship is not seen to be part of quality service provision. ISO 9001 certification on quality service provision is increasingly becoming a quest for government and private enterprises in developing countries. ISO 14001, which is squarely on environment management systems, has not been implemented in many firms more so construction companies in emerging economies, Kenya included. However, in Singapore, ISO 14001 uptake is encouraging following the success of ISO 9001 which has been implemented by contractors in Singapore with great benefits [1]. It has also been established that firms that to firms that have implemented QMS, it is easier to implement EMS [23, 24].

For sustainable development and growth of global and national economy that is growing fast and dependent on infrastructure, it is crucial to understand how the environmental impact of construction projects can be mitigated. This paper discusses adoption of environmental management systems in construction projects to reduce negative impacts associated with construction in Kenya as a developing nation. 


\section{Environmental management systems in the construction sector in emerging economies}

An EMS is a systematic approach to increasing operational efficiencies of an organisation through management of its environmental impacts $[6,7]$. It is applicable in any location to every "organization of any size or type to control the impact of its activities, products or services on the environment" [26]. ISO 14001 is a voluntary, and market-driven standard done in 1996 [27].

It constitutes policies, environmental mission statement, audits, plans, information systems, goals as well as metrics to measure and improve environmental performance condensed in 'PLAN-DO-CHECKACT' steps [8, 9]. It is a tool that closely examines operations and environmental performance enabling control, monitoring and performance improvement as well as achievement of objectives and targets [6, 7]. It enhances compliance to country environmental policies and regulations in addition to lowering environmental risks and costs. It vitally enables the fusion of environmental and business objectives in product and service design. The local, national, regional and global environment benefits while sustaining the developer's venture. It is a win-win approach to keep growth and progress in its path as emerging economies seek middle and higher income status.

The construction sector is more acquainted with ISO 9001 as environmental management practices are not very popular in the sector. Adoption of ISO 14001 certification is more widespread in developed nations. For example in Canada construction firms employ less than $2 \%$ of total firm expenditures on earning and retaining ISO 14001 certification [17]. In 2015, there was an 8\% increase of ISO 14001 certificates issued, this totalled to 319, 324 companies receiving and maintaining ISO 14001 certification globally.[18] Africa has low but growing percentage share in the overall certification more so in ISO 14001 series. Per sector readings the construction sector and affiliated industries has a low share but on an upward trend as shown in figure 1. The global growth is attributed to construction firms in developed countries undertaking the ISO 14001 certification process while in emerging economies uptake is slow and low.

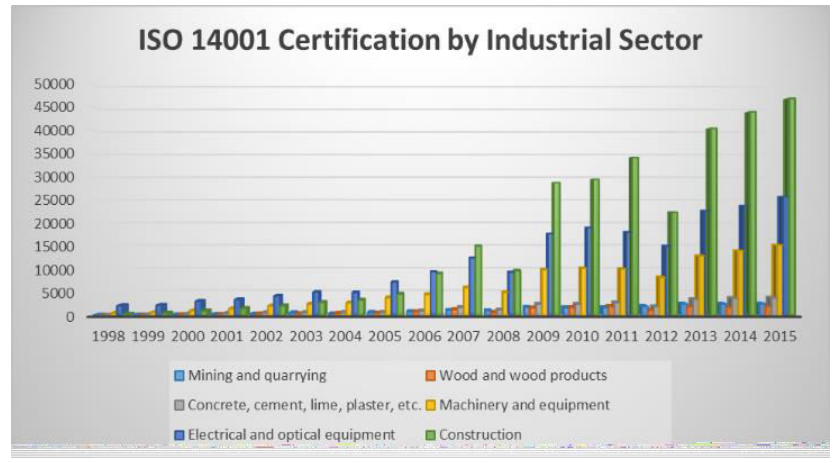

Data source: ISO survey of certifications [19]

Fig 1: ISO 14001 industrial certification in the construction sector globally.

Construction firms can opt to adopt EMS or get ISO 14001 certification guided by the company's environmental impact, market targets, environmental concerns in sites and profits [9]. 
ISO 14001 certification in Africa compared to the rest of the world is not widespread. Over the years, developing nations have been ranking lowly in environmental performance indices. Growth and development is seemingly not on a sustainable trajectory. Laxity and political interference in addressing environmental issues is to blame and worrying for these economies are natural capital dependent. For example, in 2016, Kenya ranked 120th in the country SDG index and 123rd in the environmental performance index [20,21]. As of 2015, Kenya has 50 firms (not necessarily in the construction sector) with ISO 14001 certification as illustrated in figure 2 compared to 656 institutions certified with ISO 9001 in the same year. Adoption of environmentally sustainable interventions in infrastructure design and development is minimal and is likely to stall or remain retarded without strong inclusive policy and legal framework to back the movement.

To accelerate uptake and pivot environmental conservation, integration of EMS with quality management systems as well as health and safety is key rather than doing them separately [28, 29]

Kenya has less than $1 \%$ of all ISO 14001 certifications compared to peer nations. In 2015, South Africa had 1,192 certifications, Egypt had 850, China 114,303, Malaysia-2,402, Singapore-1,630, Rwanda 1 and Nigeria 59 [19]

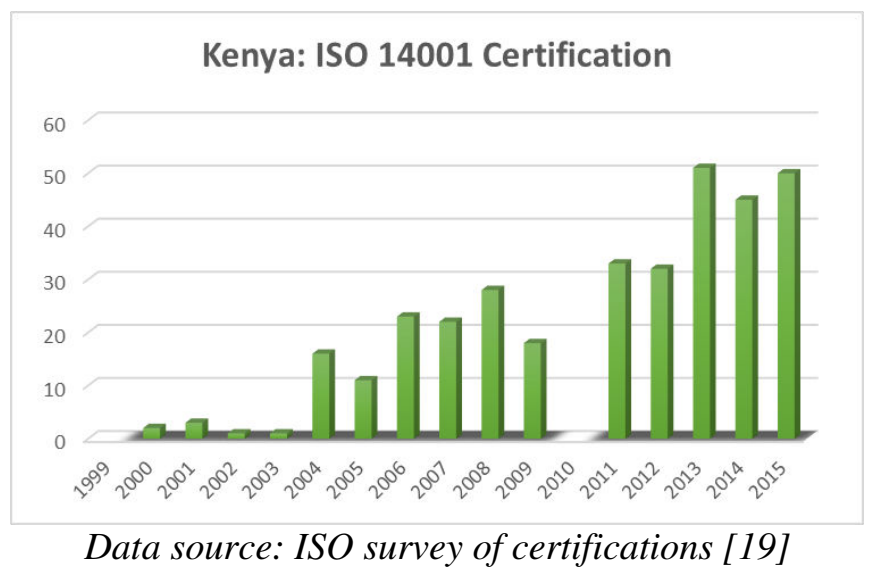

Fig 2: Number of firms in Kenya that are ISO 14001 certified in the past decade

\subsection{Drivers of adopting EMS in the construction sector in developing countries}

Unlike manufacturing entities which are proactive in managing their environmental impacts, construction firms are laggards when it comes to adopting environmental management systems. Manufacturing industries have tapped into numerous benefits associated with EMS including enhanced compliance to regulatory requirements, improved stakeholder/client relationships, reduction and opening of trade barriers facilitating doing business internationally as 'eco-citizenship' is permitting every sector globally through the green economy. Sustainable resource consumption and production has also enabled decrease in costs and risks $[7,14,30]$.

Continents that have successfully mainstreamed EMS into the construction sector attribute this to policies, government pressure and market competition. In Asia and Europe due to their global export focus, they have EMS as a procurement policy requirement and suppliers have to be registered for ISO 
14001 [31, 32]. In Australia, all construction projects are required to have a basic EMS which also addresses subcontractors. Clients demand for environmentally credible services, certified firms decline working/ subcontracting non-certified firms and this has driven EMS uptake outside policy. Top management commitment in these firms has also fostered compliance and implementation of environmental management systems. This explains the number of firms that are ISO 14001 certified in these continents $[9,33]$.

Developing countries need to step up implementation of EMS so as to widen and maintain access to global markets as well as partnerships [9] many developing nations seeing this are encouraging uptake through partially meeting certification costs for example Egypt meets $85 \%$ of the cost [34].

To loop in the construction sector, the finance sector wields more power than just policy in catalysing and achieving sustainable growth. The finance sector is pivotal in supporting a comprehensive green economy and facilitating this sensible transition from brown to green growth. EMS in construction projects in developed nations is more elaborate due to green finance. Green projects that is environmentally sound projects are funded with low interest funds.

As part of wider efforts to sustainably nurture and future proof the economy in addition to mainstreaming social and environmental considerations in developed countries, lending agencies and banks that offer green finance have carbon credit advisory services to guide clients on Clean Development Mechanisms (CDM) and Voluntary Emission Reductions (VER). They also have structured products for providing upfront finance against carbon credit receivables. Brown projects are not subjected to the same financing terms as green projects. This binds the developer to implement a project in an environmentally responsible way.

The United Kingdom has demonstrated strong leadership in this course, and has a Green Investment Bank dedicated to support the course. Additionally, UK has developed The Green Book which describes "how the economic, financial, social and environmental assessments of a policy, programme or project should be combined." The book serves to ensure that no policy, programme or project is adopted without first having the answer to these questions: "are there better ways to achieve this objective? Are there better uses for these resources?" This has enabled implementers to learn from past experience and avoid repeating past mistakes through proper evaluation of initiatives [10]. In the United States, The Heinz Endowments is a recognized financer that has extensively promoted green building in the Pittsburgh region [11]. South Africa's Financial Charter has incorporated green financing [12] of all countries studied in the 2016 World Green Buildings Trends report, South Africa has the highest green share [22].

The finance sector wields more power to enable projects comply and exceed regulatory requirements in developing countries. This can serve to overcome the inertia witnessed in the sector with regard to environmental performance. South Korea, has nurtured use of energy-saving devices by offering lowinterest loans for their purchase [13].

Further, governments can support and nurture a research and innovation ecosystem to disrupt the brown system of constructing. There are brilliant, relevant local ideas to ameliorate waste management and 
efficient resource utilisation in construction. Tasted and tried relevant technologies can also be imported. Governments can incentivize adoption through lowering and exempting taxes on sustainable technologies, equipment and accessories [9]. Indonesia a developing country has reduced tariffs on imported wastewater treatment equipment. China, a trail blazer in green finance in the developing world incentivises use of pollution control equipment, through reductions and exemptions from taxes [13]

\subsection{Barriers to adopting EMS in the construction sector in developing countries}

The construction sector has been reactive in managing environmental impacts. This informs the deficiency in apt mitigation of negative impacts and compromises gains connected with infrastructure expansion and development. As rightly observed by Massoud, Fayad, Kamleh, \& El-Fadel (2010) inept performance of the construction sector is due to wastefulness in capital (both natural and fiscal) and labour [9].

In addition, developing countries have an over-reliance on end of pipe technologies which is still attributed to the reactive approach of solving problems, lack of government and client pressure, subcontracting practices which weaken and dilute implementation of EMS, low awareness, high implementation costs as well as lack of/ inadequate top management support in firms. [9]. Therefore, energy saving and water saving equipment purchase is low and exacerbated by a financial and tax environment that is not enabling uptake of these technologies.

There are also competing needs in developing countries for subsidies. Food insecurity for example aggravated by climate change has led to subsidising food commodities. 2017 saw East African countries battling drought and governments like Kenya greatly subsidised food for citizens. The pressure this puts on emerging economies does not ease subsidising of imported technologies to ameliorate waste management. However, herein lies a solution to degradation that reduces arable land and compromises the viability of existing natural resources.

A weak framework, and inadequate solid and waste handling facilities aggravate the problem. Population growth is not factored in infrastructure development. Sewer lines, solid waste handling systems in use were built when the population numbers were less. Their capacity does not adequately handle the population explosion and concomitant effects besides demands.

In addition, inadequate training and skill development is a hindrance to adoption and implementation of EMS in the construction sector in many developing countries. This affects proper assessment and prescription of relevant mitigation measures for project activities that are out of character with the environment. [9]

Also, building green is deemed expensive as the technologies, materials and know-how are not widespread in developing countries. The learning curve of professionals acquainted with sustainable construction practices and technologies is yet to flatten in order to reduce premiums paid to engineers, green building accredited professionals and architects. There are less professionals who are well versed 
with the green building technology, EMS, and local contractors who can build green in developing countries. There is also little faith in reliability of green construction materials and technologies. Integrating green interventions from the beginning (during design) further lowers costs as compared to after project completion or making green "add-ons" during construction. Yet developers in developing countries integrate green measures on or towards project completion phases thus finding it costly and prohibitive.

In developing countries, traditional way of separating design and building activities impede environmental performance as the contractor has no say on material and technologies choice [24, 25].

Policy backing for adoption of EMS in the construction sector in developing countries is wobbly because country environmental regulations and policies are not updated to match current and future needs, they are also intentionally general and inexplicit. Sector specific breakdown of environmental regulations is inadequate or lacking. Further, implementation of the policies is marred by corruption and inadequate coordination amongst implementing government agencies whose mandates overlap.

Responsible agencies are also inadequately funded, staffed and trained to aptly execute their mandates (shared and specific). Due to inadequacy of resources they are spread too thin to implement policies and regulations, consequently sectors like construction are organized chaos and lack commitment to environmental performance which is deemed a non-issue to many.

Lack of political good will more so in sectors that are majorly government operated or with politician investments like building and construction enforcement for environmental and social compliance is low or absent [9]. This lack of environmental and social responsibility reduces/ eliminates pressure on nongovernment contractors to adopt and implement EMS. Additionally, low awareness of and lack of interest in ISO 14001 certification even in the top impacts private sector players informing the uniform behaviour in the sector. Government adoption of ISO 9001 series in most of its institutions has influenced non-government institutions to obtain it, the same can be done with ISO 14001 series [9]

Governments need to raise the floor through leading by example in resource use and waste management Government project and premises will support the old approach of command-and-control coupled with incentives to improve compliance, support conservation as well sustain economic growth and returns [13].

\subsection{Impact of EMS}

Construction projects carried out by firms that have incorporated EMS in their projects are observed to have been able to identify risks at an early stage thus helping reduce costs, overruns enabling timely completion of projects. Studies have also shown increased confidence in products, a competitive advantage, monetary savings, sustainable consumption of resources, improvement of occupational health, reduced GHG emissions, reduced generation of solid and liquid wastes, improved process efficiency and reduction of waste disposal costs $[15,16]$ 


\section{Methodology}

Researchers assessed barriers, divers and adoption levels of Environmental Management Systems in Construction firms in Kenya after adopting a standard survey with structured and open ended questions that probed on firm trades, projects, knowledge, perceptions and use of EMS. A detailed literature review enabled identification of general EMS adoption and implementation barriers and drivers. A descriptive survey tool of structured questionnaires assessing the indicators was administered to 480 contractors, engineers, architects, quantity surveyors, construction firms, project managers and construction managers. 357 questionnaires were duly filled and collected yielding a response rate of 74.3\%. Desktop study, observation and site visits of ongoing construction projects yielded information to complement the feedback from questionnaires. These findings gathered from the expert community, were analysed using SPSS, MS Excel and the evaluation informed the conclusions on EMS in construction projects in Kenya.

\section{Results}

In the study only $43.3 \%$ of the respondents reported to have incorporated sustainability measures in previous and current projects. 39.9\% of these firms have environmental policies, objectives and targets. $75 \%$ of them stated that their companies have mechanisms to capture good practice. Of these companies with mechanisms to capture good practice only $49.5 \%$ conduct external/internal environmental audits, $61.1 \%$ accept accountability for environmental performance in the projects they carry out. $41.8 \%$ stated to have adopted environmental management and evaluation technologies and only $33.2 \%$ had trained their staff on environment management and evaluation. Companies that keep a record of waste generated on the site constitutes only $45.7 \%$ of the participants. On average approximately $75 \%$ of the waste goes to the landfill while $25 \%$ is recycled.

During tendering for supplies and contracting of works sustainability and good environmental performance was reported to be important to $5.3 \%$ of the participants in the study. $80.3 \%$ of the respondents prefer to use local construction materials, labour, technologies and suppliers than foreign ones for cost reasons. None of the construction companies that took part in the study reported to have undertaken ISO14001 certification.

Environmental management in project sites was reported to be mostly the responsibility of the project manager, the contractor or site supervisor. An Environmental manager was only stated to be the overseer of environmental issues in 5 firms. Only $15.4 \%$ respondents expressed to be very confident with their knowledge on sustainable development with regard to construction industry. 36.5\% of the respondents are aware of national environmental laws and regulations applicable to the construction sector and relevant to their projects at any given time. 
For respondents who have integrated sustainability measures in projects, only $16.3 \%$ stated to have incorporated sustainability during design phase, the larger number was during construction or after construction. $68 \%$ are aware of alternative technologies and materials, however only $26.9 \%$ have switched to using them in their projects. Those who responded to having not switched at all or switched partially stated their reasons to be costs, inadequate supply, fear of being guinea pigs of these new materials and technologies yet projects had high costs attached to them and client choice influenced material and technology choice to the largest extent. $38 \%$ of the participants reported to have found use of alternative technologies and materials to increase capital costs. $63.9 \%$ of the participants attested that use of alternative technologies lowered emissions of greenhouse gases and solid waste. $71.3 \%$ stated that they could support a government intervention and mandate for EMS and green buildings. $31.7 \%$ of the participants expressed disappointment on existing enforcement measures for a sustainable and climate resilient industry.

\section{Barriers}

Barriers to implementation of EMS in Kenya were: unavailability of sustainable materials according to $18.3 \%$ of them this thus impedes apt environmental management through material selection. $43.3 \%$ identified financial costs as a barrier (seems to be the major barrier) as implementing EMS, is seen to reduce profit margins or the chance of being awarded a tender as the lowest bidder carries the day. 7.2\% stated that incompetent environmental manager is the issue while $12 \%$ felt there are insufficient incentives to support EMS mainstreaming into the construction sector. 11.5\% also expressed lack of top management support in firms to be hindering EMS integration, while $12 \%$ of the respondents expressed uncertainty about EMS measures to be a barrier together with others. Lack of environmental awareness was the third major barrier as expressed by $24.5 \%$ of the participants and $25 \%$ identified the common practise of awarding bids to lowest bidders to be a barrier to adoption and implementation of EMS. Low technical qualification of workers as a barrier was mentioned by $15.4 \%$ of the respondents as illustrated in figure 3 below. This affects environmental performance in projects as workers are not able to understand the sensitivity of environmental issues nor adequately implement solutions to mitigate environmental problems.

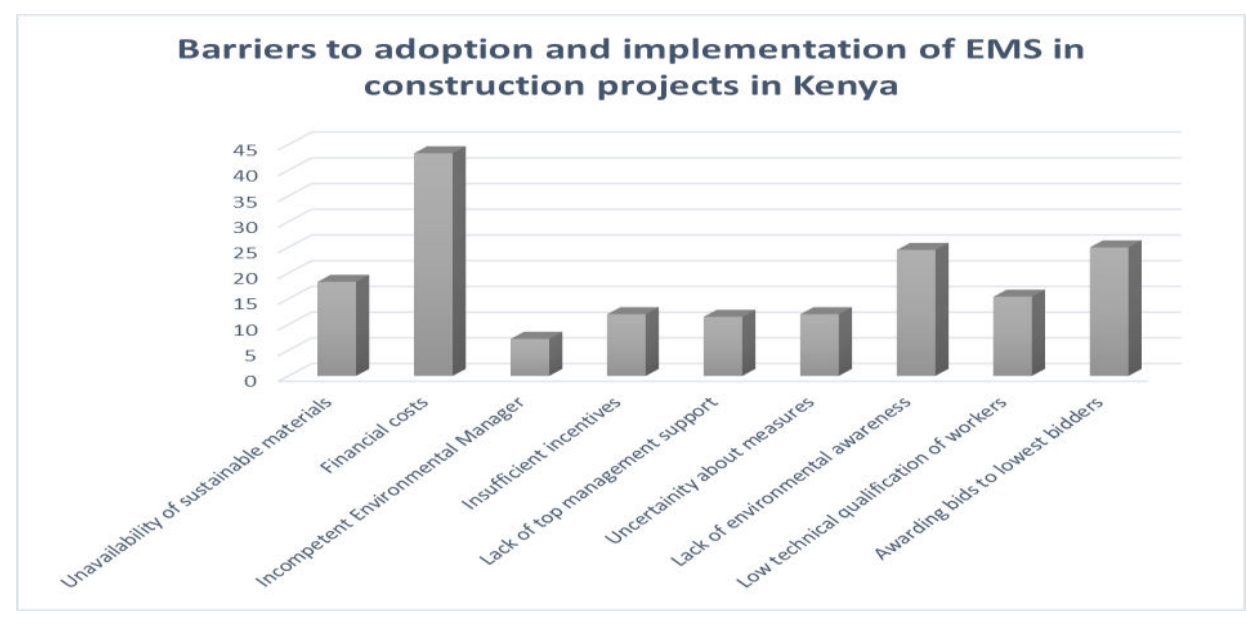


Fig 3: barriers to adoption and implementation of EMS in construction projects in Kenya

The researchers also evaluated the frequency of implementation of EMS measures in construction projects. Reducing wastage of materials was always a practice to $43.3 \%$ of them. $22.1 \%$ usually reduce energy consumption, while only $31.3 \%$ always seek to reduce air emissions. Reducing solid waste production is always a practise to $38 \%$ of the participants, and reducing wastewater production is always a measure by $40.9 \%$ though $5.3 \%$ of the respondents never consider it. Only $28.4 \%$ train all employees on hazardous waste while $37 \%$ always comply with all permits (wastewater, air quality etc).27.4\% of the participants always endeavour to reduce amount of waste going to landfills. $21 \%$ always use green procurement guidelines for projects they undertake. The frequency of employing this and the rest of the measures is as illustrated in figure 4 below.

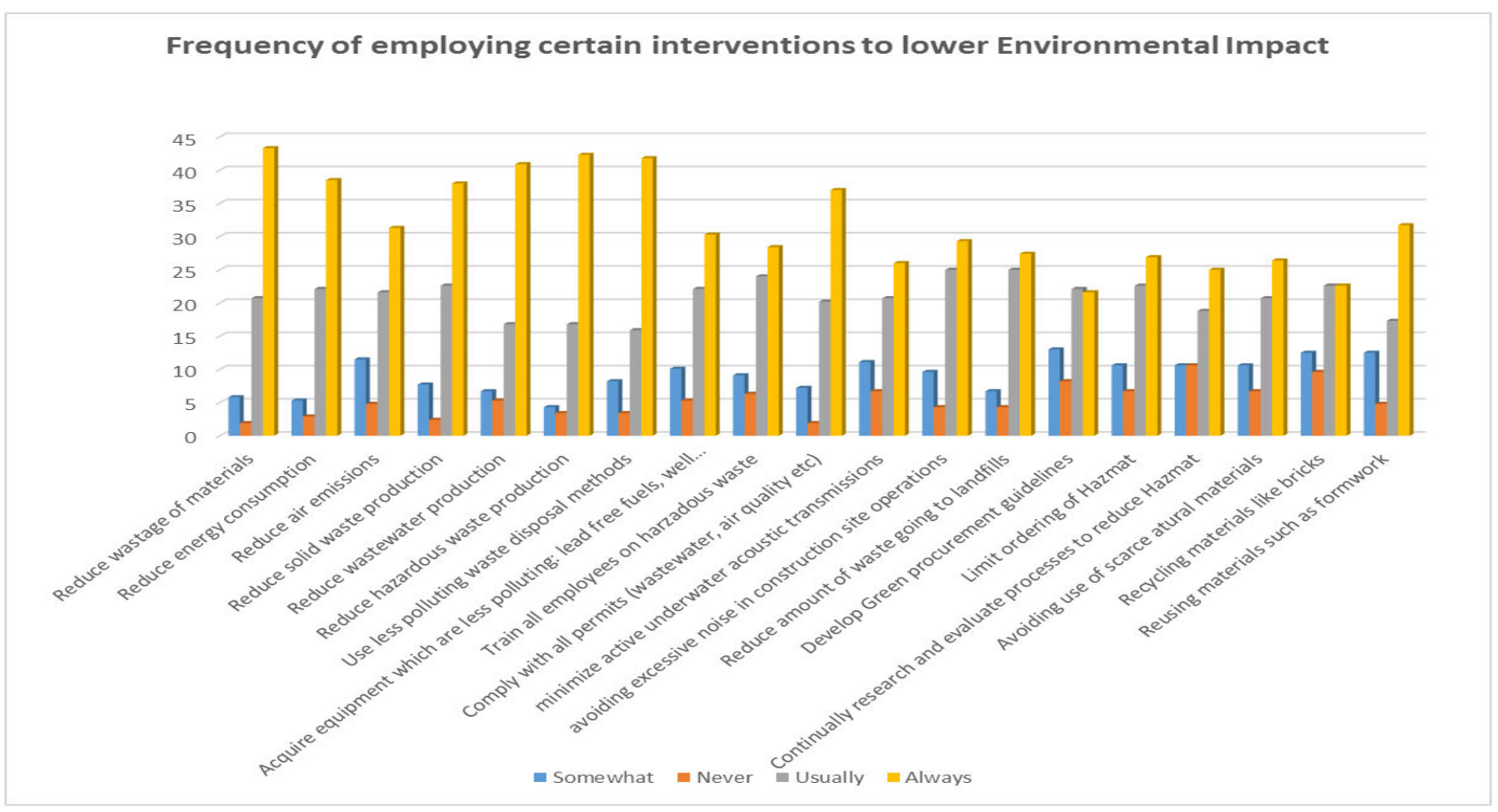

\section{Drivers}

The researchers assessed drivers to implementation and adoption of EMS and 28.4\% of the respondents expressed that legal penalties by the Government are NEVER a driver, a smaller percentage of 11.1 found it to be always a driver. Respondents expressed that due to corruption legal penalties do not drive the process. Competitive advantage over other companies was a driver to $19.9 \%$ of the respondents. Access to financing was a usual driver to $20.7 \%$ of the respondents, compliance with building codes of practice was a major driver to $34.6 \%$. Financial institutions were somewhat the drivers as stated by $14.9 \%$ of the participants. Developer choices were expressed to be the driver by $16.8 \%$ and company policies was the major driver as stated by $29.9 \%$ of the respondents Market demands and company suppliers were influencers identified by $19.7 \%$ of the respondents while employee attitudes were reported as a driver by $14.9 \%$. A summary of the results is as illustrated in figure 5 below: 


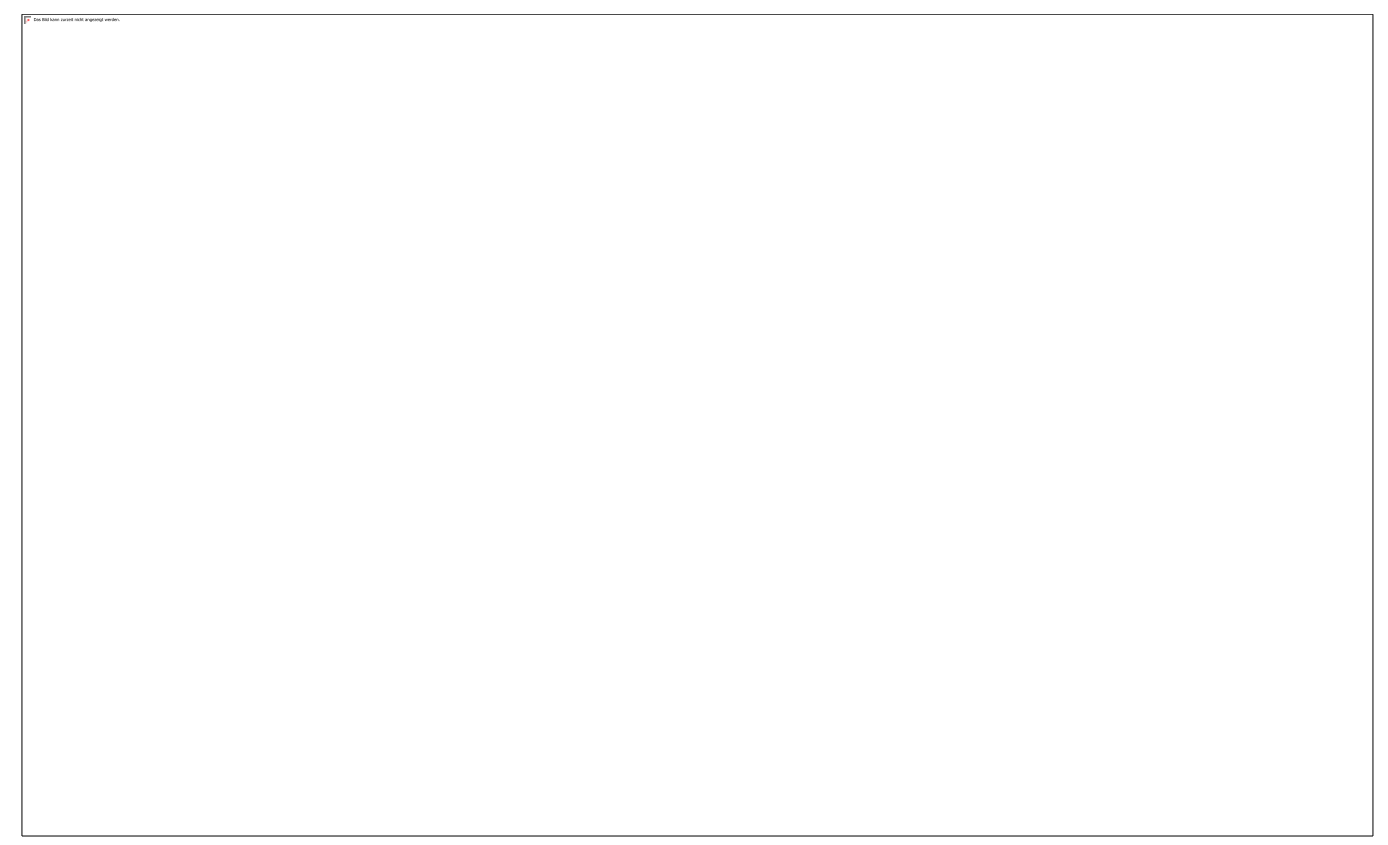

\section{Conclusion}

Fig 5: Drivers to implementation and adoption of EMS in the Construction industry in Kenya

Legal penalties against poor environmental management are not a crucial external driver for EMS in construction firms in Kenya. This is attributed to corruption and the level of harshness of the penalties. Environmental policies are not a strong internal driver for EMS adoption and implementation due to the prevailing culture and attitude towards environmental stewardship in the sector.

The fragmented nature of the industry as well as the price based economy affects adoption of EMS as the lowest bidder is awarded tenders and image of construction firms is not very crucial to them hence corporate social and environmental responsibilities take a back seat.

Sector specific government pressure and awareness of EMS needs to be increased. EMS needs to be integrated in codes as that is what industry players are aware of and follow mostly. The Government needs to incentivize adoption of standardized and non standardised EMS and even partially meet the certification costs. A database of environmentally sound materials and technologies compiled by the government and green building society can raise awareness and accelerate adoption of sustainable materials and technologies. If developing countries like Kenya do not step up their efforts on EMS in the construction sector inter alia practices, their chances for international competitiveness will remain slim and continue to narrow. 


\section{References}

[1] Ofori, G., Gang, G., \& Briffett, C. (2002). Implementing environmental management systems in construction: lessons from quality systems. Building and environment, 37(12), 1397-1407.

[2] Dixon, W. (2010). The impacts of construction and the built environment. Briefing notes, WilmottDixon Group.

[3] Eloy Maurel, E. (2013). Study on Environmental Management Systems in construction companies (Bachelor's thesis, Universitat Politècnica de Catalunya).

[4] Šelih, J. (2007). Environmental management systems and construction SMEs: a case study for Slovenia. Journal of Civil Engineering and Management, 13(3), 217-226.

[5] Tibor, T., \& Feldman, I. (1996). ISO 14000: a guide to the new environmental management standards.

[6] EPA available at: https://www.epa.gov/ems (Accessed on 25th July, 2017)

[7] Christini, G., Fetsko, M., \& Hendrickson, C. (2004). Environmental management systems and ISO 14001 certification for construction firms. Journal of Construction Engineering and Management, 130(3), 330-336.

[8] Stapleton, P. J., Glover, M. A., and Davis, S. P. 2001. "Environmental management systems: An implementation guide for small and medium-sized organizations.' Technical Rep., NSF International, Ann Arbor, Mich.

[9] Massoud, M. A., Fayad, R., Kamleh, R., \& El-Fadel, M. (2010). Environmental management system (ISO 14001) certification in developing countries: challenges and implementation strategies.

[10] Guidance, T. (2011). The green book. Appraisal and Evaluation in Central Government, London (Available

at:

https://www.gov.uk/government/uploads/system/uploads/attachment_data/file/220541/green_book_com plete. pdf [Accessed on 25 July 2017).

[11] Flora, R. L., \& Moser, M. (2000). Driving Market Demand for Green Buildings in Pittsburgh. In Green Building Alliance, Proceedings from the International Conference on Sustainable Building (pp. 70-72).

[12] UNEP. (2016) Green Finance for developing countries: Needs, Concerns, Innovations. Inquiry design of a sustainable financial system

[13] US Environmental protection Agency.International Experiences with Economic Incentives for Protecting the Environment; EPA: Washington, DC, 2004. 
[14] Johnstone, N., \& Labonne, J. (2009). Why do manufacturing facilities introduce environmental management systems? Improving and/or signaling performance. Ecological Economics, 68(3), 719-730.

[15] Chen, B. (2004). ISO 14001, EMAS, or BS 8555: An Assessment of the Environmental Management Systems for UK Businesses. Norwich, University of East Anglia.

[16] Svatikova, K., Bilsen, V., Ellis, R., Williams, R., Smith, M., \& Rademaekers, K. (2012). Study on incentives driving improvement of environmental performance of companies.

[17] Yiridoe, E. K.; Clark, J. S.; Marett, G. E.; Gordon, R.; Duinker, P. ISO 14001 EMS standard registration decisions among Canadian organizations. Agribusiness 2003, 19 (4), 439-457.

[18] The ISO survey of management system standard certifications 2015. Available at: https://www.iso.org/files/live/sites/isoorg/files/standards/conformity_assessment/certification/doc/surve y_executive-summary.pdf

[19] ISO Survey of certifications to management system standards - Full results: Available at: http://isotc.iso.org/livelink/livelink?func=ll\&objId=18808772\&objAction=browse \&viewType=1

[20] Index, E. P. (2016). Global Metrics for the Environment: The Environmental Performance Index Ranks Countries' Performance on High-Priority Environmental Issues-2016 Report.

[21] Sachs, J., Schmidt-Traub, G., Kroll, C., Durand-Delacre, D., \& Teksoz, K. (2016). SDG Index and dashboards - a global report. New York: Bertelsmann Stiftung and Sustainable Development Solutions Network (SDSN).

[22] Buckley, B., \& Logan, K. (2016). World green building trends 2016: developing markets accelerate global green growth. Bedford (MA): Dodge Data \& Analytics.

[23] Griffith, A. Integrated management systems: a single management system for project control? Engineering, Construction and Architectural Management, 2000, 7(3), p. 232-240.

[24] Jana Šelih (2007) Environmental management systems and construction SMES: A case study for Slovenia, Journal of Civil Engineering and Management, 13:3, 217-226

[25] Ling, F. Y. Y.; Chan, S. L.; Chong, E. and EE, L. P. Predicting performance of design-build and design-bidbuild projects. ASCE Journal of Construction Engineering and Management, 2004, 30(1), p. 75-83.

[26] International Organization for Standardization $\sim$ ISO. 2002. "The basics: ISO 14000 and environmental management systems for busy managers." ${ }^{\wedge}$ Www.iso.ch/iso/en/iso900014000/tour/14kbusy.html\& October 2002!

[27] Kloepfer, R. J. 1997. “Will the real ISO 14001 please stand up?’' Civ. Eng. (N.Y.), 67 11, 45-47

[28] Griffith, A. 2000. "Integrated management systems: a single management system solution for project control?'” Eng., Constr., Archit. Manage., 7 3, 232-240. 
[29] Shen, Y. J., and Walker, D. H. T. 2001. “'Integrating OHS, EMS and QM with constructability principles when construction planning-A design and construct project case study.' TQM Mag., 13 4, 247-259

[30] Powers, M. B. 1995. “Companies await ISO 14000 as primer for global eco-citizenship.' ENR, 234 21, 30-32.

[31] Zutshi, A.; Sohal, A. Environmental management system adoption by Australasian organizations. Part 1: reasons, benefits and impediments. Technovation 2004, 24 (4), 335-357.

[32] Chen, C. Incorporating green purchasing into the frame of ISO 14000. J. Clean. Prod. 2005, 13, 927-933.

[33] Sambasivan, M.; Yun Fei, N. Evaluation of critical success factors of implementation of ISO 14001 using analytic hierarchy process (AHP): a case study from Malaysia. J. Clean. Prod. 2008, 16, 14241433.

[34] Peglau, R.; Baxter, M. A Decade of ISO 14001, special report 2007; Available at http://www.iso.org/ims 